\title{
The neurological manifestations of COVID-19: a review article
}

\author{
Hamid Reza Niazkar ${ }^{1}$ (D) $\cdot$ Behdad Zibaee $^{1}$ (D) Ali Nasimi $^{1}$ (D) $\cdot$ Narjes $^{\text {Bahri }}{ }^{2}$ (D)
}

Received: 16 April 2020 / Accepted: 21 May 2020 / Published online: 1 June 2020

(C) Fondazione Società Italiana di Neurologia 2020

\begin{abstract}
Results Various neurological manifestations have been reported in the literature associated with COVID-19, which in the current study are classified into Central Nervous System (CNS) related manifestations including headache, dizziness, impaired consciousness, acute cerebrovascular disease, epilepsy, and Peripheral Nervous System (PNS) related manifestations such as hyposmia/anosmia, hypogeusia/ageusia, muscle pain, and Guillain-Barre syndrome.

Conclusion During the current context of COVID-19 pandemic, physicians should be aware of wide spectrum of neurological COVID-19 sign and symptoms for early diagnosis and isolation of patients. In this regard, COVID-19 has been associated with many neurological manifestations such as confusion, anosmia, and ageusia. Also, various evidences support the possible CNS roles in the COVID-19 pathophysiology. In this regard, further investigation of CNS involvement of SARS-COV-2 is suggested.
\end{abstract}

Keywords Coronaviruses · SARS-COV-2 · COVID-19 · Neurological symptoms

\section{Introduction}

The severe acute respiratory syndrome coronavirus 2 (SARSCOV-2) was first identified in Wuhan, China in December 2019. Coronaviruses are zoonotic pathogens for humans and vertebrates, which are notorious for the outbreaks of the Severe Acute Respiratory Syndrome (SARS) and the Middle East Respiratory Syndrome (MERS) in 2002-2003 and 2012, respectively. The rapid spread of the SARS-COV-2 and the unknown nature of the disease have led to a vigorous pandemic in March 2020. To this date (10 April 2020), more than 1 million people worldwide have been infected, and more than 60,000

Narjes Bahri

nargesbahri@yahoo.com

Hamid Reza Niazkar

hrn185@hotmail.com

Behdad Zibaee

behdad.zbe73@gmail.com

Ali Nasimi

alsnasimi@gmail.com

1 Student Research Committee, Faculty of Medicine, Gonabad University of Medical Sciences, Gonabad, Iran

2 Department of Midwifery, Faculty of Medicine, Social Development and Health Promotion Research Center, Gonabad University of Medical Sciences, Gonabad, Iran people have died due to the COVID-19. In a bid to overcome this outbreak, numerous researches are being conducted in different aspects of the COVID-19 outbreak including diagnosis, management, and treatment of the disease [1-3].

Studies reported a wide spectrum of signs and symptoms associated with COVID-19 including nonproductive cough, fever, myalgia, fatigue, dyspnea, diarrhea, and nausea/vomiting while some patients are known to be asymptomatic [3]. The incubation period of COVID-19 is assumed to be between 2 and 11 days with an approximate mortality rate of 2 to $4 \%$ [4, 5]. According to the studies, infected individuals produce a large quantity of virus in the upper respiratory tract during the incubation period, which leads to the latent spread of infection. Whether the asymptomatic and/or treated individuals can transmit the virus or not is not completely clear yet [6]. The diagnosis of COVID-19 relies on clinical suspicion, CT findings, and reverse transcription polymerase chain reaction molecular test (RTPCR). Since neither an effective drug nor a vaccine is currently available for the COVID-19, early diagnosis and isolation of the patients play a crucial role in controlling the outbreak. Additionally, there are many possible atypical clinical presentations in COVID-19 patients, which may be un-/misdiagnosed [7].

According to studies, more than 35\% of COVID-19 patients develop neurological symptoms. Some COVID-19 patients may present neurologic symptoms as the initial presentations of the disease [8]. However, the prevalence of neurological signs and 
symptoms is higher in patients with severe COVID-19 infection, which may be the result of cerebral hypoxia due to respiratory failure [9]. In the current study, we aimed to review the neurological manifestation of COVID-19. For this purpose, neurological signs and symptoms were categorized into the Central Nervous System (CNS) associated and Peripheral Nervous System (PNS) associated ones. Needless to say, such studies will raise the clinical suspicion of a physician for early diagnosis of the COVID-19.

\section{CNS associated sign and symptoms}

Several CNS-related manifestations have been reported in the literature associated with COVID-19, including headache, dizziness, impaired consciousness, acute cerebrovascular disease, epilepsy, ataxia, acute disseminated encephalomyelitis (ADEM), and viral encephalitis, which are explained briefly in the following $[5,9]$ :

Headache is the most common CNS symptoms with the prevalence varying from 6.5 to $23 \%$, and the mean prevalence of $8 \%$ in different studies [10]. In a study by Wang et al., among 138 hospitalized patients with COVID-19, thirteen patients had dizziness and nine patients had a headache. Also, those in the intensive care unit were more likely to report dizziness [11].

Older individuals especially those with preexisting chronic medical conditions are at an elevated risk of impaired consciousness or delirium in the setting of acute infections, these patients which are prone to experience COVID-19 severely, may present with encephalopathy and confusion [12]. In a study, confusion was reported in $9.0 \%$ of the COVID-19 patients mostly in those with poor prognosis [13]. Moreover, confusion or impaired consciousness may be a result of intracranial hemorrhages. For instance, recently a case of massive intracerebral hemorrhage (ICH) in a COVID-19 patient is reported in Iran [14]. This raised the question of whether the dysfunction of angiotensin II receptors expressed in cerebrovascular endothelial cells of the brain could be associated with COVID19 infection and ICH. The authors hypothesized that the dysfunction of angiotensin II receptors due to the SARS-COV-2 invasion may lead to disruption of water and sodium regulation leading to the rupture of arterial wall [14].

Cerebrovascular diseases are one of the most common comorbidities in patients suffering from severe COVID-19 [15]. Furthermore, viral infections such as COVID-19 may provoke the occurrence of cerebrovascular diseases (CVD) such as acute ischemic stroke as well $[5,16]$. This may be due to the downregulation of natural anticoagulant mechanisms by inflammatory mediators and disturbance of coagulation system. In this regard, similar to MERS, disruption of the coagulation system is reported in the COVID-19 patients [17]. Some critically ill patients with COVID-19 have a significant tendency for clot formation [18]. In such cases, administration of anticoagulant drugs appears to be associated with better prognosis in severe COVID-19 patients due to decreasing the risk of venous thromboembolism [19].

Several cases of recurrent transient generalized tonic-clonic seizures in patients with COVID-19 have been reported in the literature. All those cases neither had a history of epileptic seizures nor a family history of seizure disorders [20-22]. In this regard, physicians should be aware of the contraindication administration of hydroxychlocoquine [23, 24]. Several hypotheses are proposed for explaining COVID-19-associated epilepsy including the release of inflammatory cytokines, tumor necrotizing $\alpha$, and the granulocyte colony-stimulating factor, which can trigger neuronal hyperexcitability through activation of glutamate receptors leading to episodic seizures $[25,26]$. On the other hand, some researchers believe that seizures may be due to encephalitis and the invasion of the virus to the brain [27]. However, whether the SARS-COV-2 virus can cross the blood-brain barrier (BBB) or not is still controversial $[5,28]$. It should be mentioned that epilepsy may also be associated with the adverse drug reaction of antiviral drugs, such as lopinavir/ritonavir and ribavirin in some cases [29].

Acute necrotizing encephalopathy (ANE) is a rare progressive neurodegenerative disorder characterized by multiple, symmetric areas of edema and necrosis in the CNS, which is known to be due to the uncontrolled release of cytokines during a febrile disease such as influenza [30,31]. ANE leads to disruption of BBB without direct viral invasion. Recently a case of ANE is reported in a COVID-19 [30].

Limited cases of ataxia, ADEM, are reported in the COVID19 patients [32, 33]. Nevertheless, more convening evidence is required in this purpose.

\section{PNS-associated sign and symptoms}

PNS sign and symptoms of COVID-19 are less severe, including hyposmia/anosmia, hypogeusia/ageusia, muscle pain, and Guillain-Barre syndrome (GBS), which are described in the following [34]:

Anosmia and ageusia are the most common PNS manifestations of SARS-COV-2, which has also been reported in previous coronaviruses. These symptoms occur suddenly, and usually with fewer nasal symptoms such as nasal obstruction or excessive nasal secretion [35]. Anosmia and ageusia are mostly present in asymptomatic individuals or as the initial presentation of the disease with no other symptoms [36]. Therefore, some researchers suggested that people with such symptoms may be possible carriers and should isolate themselves from others. Most patients gradually regain their sense of taste and smell as they recover from SARS-COV-2 infection [37].

The exact mechanisms associated with SARS-COV-2 anosmia are not clear yet. However, several hypotheses are proposed for explaining anosmia. According to a study in animal models, 
coronavirus can transneuronally disseminate into the brain through olfactory pathways and invade the olfactory neuroepithelium integrity through the expression of TMPRSS2 and ACE2 in sustentacular cells $[38,39]$. Consequently, disruption of olfactory neuroepithelium leads to anosmia. Nevertheless, some authors believe that anosmia is somehow due to inflammation in the olfactory nerves rather than damage to the structure of the receptors [40]. However, application of nasal corticosteroids is not suggested due to the uncertainty of their benefits [37].

\section{Discussion}

COVID-19 is a novel respiratory disease caused by SARS-COV2 , which has become the biggest health concern worldwide. COVID-19 may accompany a wide range of signs and symptoms including fever, cough, rhinorrhea, chest pain, diarrhea, vomiting, nausea, confusion, etc. Whereas, some patients may be asymptomatic [6]. The diagnosis of COVID-19 is made through suspicious clinical symptoms and imaging [7]. In this regard, some clinical and laboratory manifestations of the COVID-19 may be uncommon or neglectable, leading to the un-/misdiagnose of the disease and further contaminations of individuals.

Based on conducted studies, more than one-third of COVID-19 patients present neurological symptoms during the course of the disease. Even in some patients, neurologic symptoms may be the initial or only presentations of the COVID-19. Additionally, the prevalence of neurological signs and symptoms is higher in patients with severe COVID-19 infection $[6,8]$.
The reported neurological sign and symptoms of COVID19 include headache, dizziness, confusion, acute cerebrovascular disease, epilepsy, ataxia, anosmia, ageusia, and muscle pain demyelinating encephalomyelitis [9]. In this regard, CVDs are not only one of the main comorbidities of COVID-19 patients, but also individuals with risk factors may experience CVDs in the context of COVID-19 pathophysiology. The hyperactivation of inflammatory factors disrupts the coagulation system leading to D-dimer and platelet abnormalities [5], which spikes the risk of CVDs. Furthermore, administration of anticoagulants is showed to decrease the mortality rate of hospitalized patients [19].

Anosmia and ageusia are known to be a common PNS manifestation of COVID-19 especially in those assumed to be asymptomatic [35, 36]. Some individuals with anosmia later develop respiratory symptoms while others remain asymptomatic. In this regard, these symptoms should raise the suspicion of COVID-19 diagnosis even in the absence of other typical symptoms in the current pandemic [40]. Anosmia and ageusia may be associated with the increased ACE-2 receptors expressed in nasal mucosa and tongue [41]. Whether anosmia and ageusia are the results of nerve injuries or inflammation of the olfactory nerves is still disputable. Since brain stem involvement has been reported previously in patients and animal models of severe acute respiratory syndrome coronavirus (SARS-CoV) infection, some researchers believe that peripheral trigeminal or olfactory nerves are pathways for coronaviruses to enter the CNS. However, further studies are required [5].

Patients with severe CNS involvement present with lower lymphocyte and platelet counts beside higher blood urea
Fig. 1 Deadly vicious cycle of pneumonia, hypoxia, and cardiorespiratory regulation nuclei of brain stem

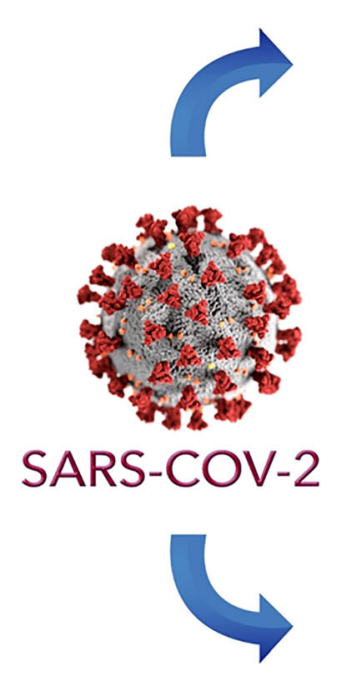

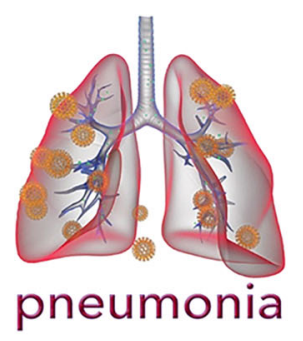
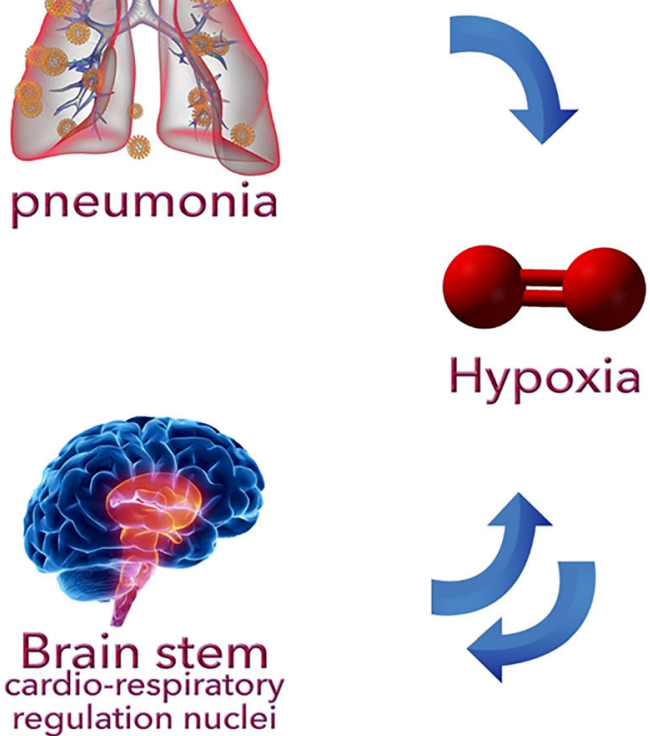
nitrogen levels, while laboratory findings may not be helpful in patients with PNS involvement or individuals with nonsevere CNS involvement [9].

Various mechanisms are proposed for explaining the possible CNS involvement of the SARS-COV-2 including direct invasion of the virus via disruption of BBB through release of cytokines and retro- or anterograde neuronal transport via dynein and kinesins proteins [5]. In addition, possible nerves injuries may also be mediated by the immune system, hypoxia resulted by pneumonia, and/or through attaching to ACE2 receptors [5]. These receptors are known to be expressed in different organs including CNS, lungs, arteries, heart, kidney, and intestines. ACE2 receptors regulate blood pressure and according to the studies, SARS-CoV-2 spike protein could interact with ACE2 receptors, leading to elevated blood pressure and increase the risk of cerebral hemorrhage [14, 42]. With similar mechanism, SARS-COV-2 binding with ACE2 receptors of capillary endothelium may disrupt the BBB and enter the CNS. In a study, Steardo et al. indicated that coronaviruses infect brain stem neurons, which are responsible for the cardio-respiratory regulation, resulting in the respiratory failure and hypoxia [43]. It seems that on one hand, SARS-COV-2 leads to both pneumonia and impairment of brain stem cardio-respiratory regulation center, which both leads to hypoxia. On the other hand, hypoxia may exacerbate the neural damage leading to a deadly vicious cycle as shown in Fig. 1. This supports the higher prevalence of neurological symptoms in severely ill patients. Considering the lack of evidences and the importance of possible CNS roles in the COVID-19 pathophysiology, further studies are encouraged.

Conclusion During the current context of COVID-19 pandemic, physicians should be aware of wide spectrum of neurological COVID-19 sign and symptoms for early diagnosis and isolation of patients. In this regard, COVID-19 has been associated with many neurological manifestations such as confusion, anosmia, and ageusia. Various evidences support the possible CNS roles in the COVID-19 pathophysiology. In this regard, further investigation of CNS involvement of SARSCOV-2 is suggested.

\section{Compliance with ethical standards}

Conflict of interest The authors declare that they have no conflict of interest.

\section{References}

1. WHO Coronavirus disease (COVID-2019) situation reports [Available from: https://www.who.int/emergencies/diseases/ novel-coronavirus-2019/situation-reports

2. Niazkar HR, Niazkar M (2020) COVID-19 international outbreak and the need for a suitable estimation model: a second-order polynomial equation with constant coefficients based on imported infected cases seems inadequate. Asian Pac J Trop Med 13(4):185186. https://doi.org/10.4103/1995-7645.280234

3. Niazkar M, Niazkar HR (2020) COVID-19 outbreak: application of multi-gene genetic programming to country-based prediction models. Electronic J Gen Med 17(5):em247. https://doi.org/10. 29333/ejgm/8232

4. Lauer SA, Grantz KH, Bi Q, Jones FK, Zheng Q, Meredith HR, Azman AS, Reich NG, Lessler J (2020) The incubation period of coronavirus disease 2019 (COVID-19) from publicly reported confirmed cases: estimation and application. Ann Intern Med 172(9): 577-582. https://doi.org/10.7326/M20-0504

5. Wu Y, Xu X, Chen Z, Duan J, Hashimoto K, Yang L et al (2020) Nervous system involvement after infection with COVID-19 and other coronaviruses. Brain Behav Immun. https://doi.org/10.1016/j. bbi.2020.03.031

6. Bai Y, Yao L, Wei T, Tian F, Jin D-Y, Chen L, Wang M (2020) Presumed asymptomatic carrier transmission of COVID-19. Jama. 323:1406. https://doi.org/10.1001/jama.2020.2565

7. Wang Y, Kang H, Liu X, Tong Z (2020) Combination of RT-qPCR testing and clinical features for diagnosis of COVID-19 facilitates management of SARS-CoV-2 outbreak. J Med Virol 92:538-539. https://doi.org/10.1002/jmv.25721

8. Jiang F, Deng L, Zhang L, Cai Y, Cheung CW, Xia ZJJGIM (2020) Review of the clinical characteristics of coronavirus disease 2019 (COVID-19):1-5. https://doi.org/10.1007/s11606-020-05762-w

9. Azhideh A (2020) COVID-19 Neurological Manifestations. Int Clin Neurosci J 7(2):54. https://doi.org/10.34172/icnj.2020.01

10. Rodriguez-Morales AJ, Cardona-Ospina JA, Gutiérrez-Ocampo E, Villamizar-Peña R, Holguin-Rivera Y, Escalera-Antezana JP, Alvarado-Arnez LE, Bonilla-Aldana DK, Franco-Paredes C, Henao-Martinez AF, Paniz-Mondolfi A, Lagos-Grisales GJ, Ramírez-Vallejo E, Suárez JA, Zambrano LI, Villamil-Gómez WE, Balbin-Ramon GJ, Rabaan AA, Harapan H, Dhama K, Nishiura H, Kataoka H, Ahmad T, Sah R, Latin American Network of Coronavirus Disease 2019-COVID-19 Research (LANCOVID-19). Electronic address: https://www.lancovid.org (2020) Clinical, laboratory and imaging features of COVID-19: a systematic review and meta-analysis. Travel Med Infect Dis 101623:101623. https://doi.org/10.1016/j.tmaid.2020.101623

11. Wang Y, Wang Y, Chen Y, Qin QJJ (2020) Unique epidemiological and clinical features of the emerging 2019 novel coronavirus pneumonia (COVID-19) implicate special control measures. J Med Virol 92(6). https://doi.org/10.1002/jmv.25748

12. Filatov A, Sharma P, Hindi F, Espinosa PS (2020) Neurological complications of coronavirus disease (COVID-19): encephalopathy. Cureus. 12(3):e7352. https://doi.org/10.7759/cureus. 7352

13. Chen N, Zhou M, Dong X, Qu J, Gong F, Han Y, Qiu Y, Wang J, Liu Y, Wei Y, Xia J', Yu T, Zhang X, Zhang L (2020) Epidemiological and clinical characteristics of 99 cases of 2019 novel coronavirus pneumonia in Wuhan, China: a descriptive study. Lancet 395(10223):507-513. https://doi.org/10.1016/ S0140-6736(20)30211-7

14. Sharifi-Razavi A, Karimi N, Rouhani N (2020) COVID-19 and intracerebral haemorrhage: causative or coincidental? New Microbes New Infect 35:100669. https://doi.org/10.1016/j.nmni. 2020.100669

15. Wang L, He W, Yu X, Hu D, Bao M, Liu H, Zhou J, Jiang H (2020) Coronavirus disease 2019 in elderly patients: characteristics and prognostic factors based on 4-week follow-up. J Inf Secur 80: 639-645. https://doi.org/10.1016/j.jinf.2020.03.019

16. Morelli N, Rota E, Terracciano C, Immovilli P, Spallazzi M, Colombi D, Zaino D, Michieletti E, Guidetti D (2020) The baffling case of ischemic stroke disappearance from the casualty department in the COVID-19 era. Eur Neurol 1:1-3. https://doi.org/10.1159/ 000507666 
17. Giannis D, Ziogas IA, Gianni P (2020) Coagulation disorders in coronavirus infected patients: COVID-19, SARS-CoV-1, MERS$\mathrm{CoV}$ and lessons from the past. J Clin Virol 104362:104362. https:// doi.org/10.1016/j.jcv.2020.104362

18. Violi F, Pastori D, Cangemi R, Pignatelli P, Loffredo L (2020) Hypercoagulation and antithrombotic treatment in coronavirus 2019: a new challenge. Thromb Haemost. https://doi.org/10.1055/ s-0040-1710317

19. Tang N, Bai H, Chen X, Gong J, Li D, Sun Z (2020) Anticoagulant treatment is associated with decreased mortality in severe coronavirus disease 2019 patients with coagulopathy. J Thromb Haemost 18:1094-1099. https://doi.org/10.1111/jth. 14817

20. Karimi N, Sharifi Razavi A (2020) Rouhani NJIRCMJ. Frequent convulsive seizures in an adult patient with COVID-19: a case report. Iran Red Crescent Med J (In Press). https://doi.org/10. 5812/ircmj.102828

21. Yasri S, Wiwanikit V (2020) COVID-19 and epilepsy. Ann Indian Acad Neurol 23(7):43. https://doi.org/10.4103/aian.AIAN_254_20

22. Lu L, Xiong W, Liu D, Liu J, Yang D, Li N, Mu J, Guo J, Li W, Wang G, Gao H, Zhang Y, Lin M, Chen L, Shen S, Zhang H, Sander JW, Luo J, Chen S, Zhou D (2020) New-onset acute symptomatic seizure and risk factors in corona virus disease 2019: a retrospective multicenter study. Epilepsia. https://doi.org/10.1111/ epi. 16524

23. Nicastri E, Petrosillo N, Bartoli TA, Lepore L, Mondi A, Palmieri F et al (2020) National Institute for the Infectious Diseases "L. Spallanzani”, IRCCS. Recommendations for COVID-19 clinical management. 12(1). https://doi.org/10.4081/idr.2020.8543

24. Badyal DK, Mahajan RJIJA (2020) Research BM. Chloroquine 10(2):128. https://doi.org/10.4103/ijabmr.IJABMR_141_20

25. Libbey JE, Fujinami RSJF (2011) Neurotropic viral infections leading to epilepsy: focus on Theiler's murine encephalomyelitis virus. 6(11):1339-1350. https://doi.org/10.2217/fvl.11.107

26. Singhi PJDM (2011) Neurology C Infectious causes of seizures and epilepsy in the developing world. 53(7):600-609. https://doi.org/ 10.1111/j.1469-8749.2011.03928.x

27. Moriguchi T, Harii N, Goto J, Harada D, Sugawara H, Takamino J et al (2020) A first case of meningitis/encephalitis associated with SARS-coronavirus-2. https://doi.org/10.1016/j.ijid.2020.03.062

28. Filatov A, Sharma P, Hindi F, Espinosa PSJC (2020) Neurological complications of coronavirus disease (covid-19): encephalopathy. 12(3):e7352. https://doi.org/10.7759/cureus.7352

29. Ying W, Qian Y, Kun ZJRS, Pharmacy A (2020) Drugs supply and pharmaceutical care management practices at a designated hospital during the COVID-19 epidemic. https://doi.org/10.1016/j.sapharm. 2020.04.001

30. Poyiadji N, Shahin G, Noujaim D, Stone M, Patel S, Griffith B (2020) COVID-19-associated acute hemorrhagic necrotizing encephalopathy: CT and MRI features. Radiology. 201187:201187. https://doi.org/10.1148/radiol.2020201187
31. Kansagra SM, Gallentine WB (2011) Cytokine storm of acute necrotizing encephalopathy. Pediatr Neurol 45(6):400-402. https://doi. org/10.1016/j.pediatrneurol.2011.09.007

32. Baig AM (2020) Neurological manifestations in COVID-19 caused by SARS-CoV-2. CNS Neurosci Therapeut 26(5):499-501. https:// doi.org/10.1111/cns.13372

33. McAbee GN, Brosgol Y, Pavlakis S, Agha R, Gaffoor M (2020) Encephalitis associated with COVID-19 infection in an 11 year-old child. Pediatr Neurol. https://doi.org/10.1016/j.pediatrneurol.2020. 04.013

34. Sedaghat Z, Karimi N (2020) Guillain Barre syndrome associated with COVID-19 infection: a case report. J Clin Neurosci. https:// doi.org/10.1016/j.jocn.2020.04.062

35. Vaira LA, Salzano G, Deiana G, De Riu G (2020) Anosmia and ageusia: common findings in COVID-19 patients. Laryngoscope. https://doi.org/10.1002/lary.28692

36. Gane SB, Kelly C, Hopkins C (2020) Isolated sudden onset anosmia in COVID-19 infection. A novel syndrome. Rhinology. https:// doi.org/10.4193/rhin20.114

37. Ovesen T (2020) COVID-19 anosmia. Tidsskrift for Den norske legeforening. https://doi.org/10.4045/tidsskr.20.0302

38. Xydakis MS, Dehgani-Mobaraki P, Holbrook EH, Geisthoff UW, Bauer C, Hautefort C, Herman P, Manley GT, Lyon DM, Hopkins C (2020) Smell and taste dysfunction in patients with COVID-19. Lancet Infect Dis. https://doi.org/10.1016/S1473-3099(20)30293-0

39. Moein ST, Hashemian SM, Mansourafshar B, Khorram-Tousi A, Tabarsi P, Doty RL. Smell dysfunction: a biomarker for COVID19. International Forum of Allergy \& Rhinology 2020. https://doi. org/10.1002/alr.22587

40. Villalba NL, Maouche Y, MBA O, Sosa ZC, Chahbazian JB, Syrovatkova A et al (2020) Anosmia and dysgeusia in the absence of other respiratory diseases: should COVID-19 infection be considered? Eur J Case Rep Int Med 7(4). https://doi.org/10.12890/ 2020_001641

41. Vaira LA, Salzano G, Fois AG, Piombino P, De Riu G. Potential pathogenesis of ageusia and anosmia in COVID-19 patients. International Forum of Allergy \& Rhinology 2020. https://doi.org/ 10.1002/alr.22593

42. Liu Z, Xiao X, Wei X, Li J, Yang J, Tan H, Zhu J, Zhang Q, Wu J, Liu L (2020) Composition and divergence of coronavirus spike proteins and host ACE2 receptors predict potential intermediate hosts of SARS-CoV-2. J Med Virol 92(6):595-601. https://doi. org/10.1002/jmv. 25726

43. Steardo L, Zorec R, Verkhratsky A (2020) Neuroinfection may potentially contribute to pathophysiology and clinical manifestations of COVID-19. Acta Physiol. https://doi.org/10.1111/apha. 13473

Publisher's note Springer Nature remains neutral with regard to jurisdictional claims in published maps and institutional affiliations. 